\title{
INVERSÃO DO ÔNUS DA PROVA: EQUILÍBRIO NA RELAÇÃO DE CONSUMO
}

\author{
Fúlvia Leticia Perego Silva; Danton Gabriel Pain. \\ Universidade do Oeste Paulista-UNOESTE, Mestrado em Meio Ambiente e Desenvolvimento Regional - MMADRE, \\ Presidente Prudente/SP. E-mail: fulvialeticia.adv@uol.com.br.
}

\begin{abstract}
RESUMO
O Código de Defesa do Consumidor trouxe uma das maiores inovações do direito processual civil, prevista em seu artigo 60 , inciso VIII, que possibilita ao juiz determinar, a inversão do ônus da prova, a favor do destinatário final de bens e serviços, quando for verossímil a alegação ou quando se tratar de consumidor hipossuficiente. Dessa forma, o presente artigo tem por objetivo verificar o benefício da inversão do ônus da prova na relação entre consumidor e fornecedor. Utilizou-se como metodologia a pesquisa eminentemente bibliográfica e exploratória. Conclui-se que a inversão do ônus da prova na relação consumerista é de fundamental importância para o equilíbrio processual entre o consumidor e o fornecedor, tendo em vista que aquele, na maioria das vezes, é a parte mais vulnerável na relação processual, buscando-se tão somente salvaguardar a facilitação da defesa de seu direito em juízo.

Palavras-chave: Inversão do ônus da prova. Código de Defesa do Consumidor. Direito básico. Consumidor. Fornecedor.
\end{abstract}

\section{REVERSAL OF BURDEN OF PROOF: BALANCING THE CONSUMPTION RATIO}

\begin{abstract}
The Consumer Defense Code brought a major innovation in the civil procedural law, provided for in article 6, section VIII, which allows the court to determine the reversal of the burden of proof in favor of the final goods and services recipient, when the allegation is probable or in the case of a disadvantage consumers. Thus, this article aims to verify the benefit of reversing the burden of proof on the relationship between consumer and supplier. It was used as a methodology eminently bibliographic and exploratory research. It is concluded that the reversal of the burden of proof in consumerist relationship is of fundamental importance to the procedural balance between the consumer and the supplier with a view to that, most often, is the most vulnerable part of the procedural relationship, seeking solely to safeguard the facilitation of defending their rights in court.
\end{abstract}

Keywords: The burden of proof inversion. Consumer protection code. Basic right. Consumer. Provider. 


\section{INTRODUÇÃO}

A inversão do ônus da prova descrita no artigo 6으, inciso VIII $^{1}$ do Código de Defesa do Consumidor ou Lei 8.078 de 1990 é um dos mais importantes instrumentos que o consumidor encontra para a facilitação da sua defesa. Sendo, portanto, um direito básico, que reconhece a vulnerabilidade do consumidor na relação deste com o fornecedor de produtos e serviços.

Segundo a legislação consumerista, a inversão do ônus da prova em favor do consumidor deve ser garantida em função da sua hipossuficiência técnica e econômica em relação ao fornecedor. A facilitação dos direitos do consumidor deve ser vista como forma de garantir o equilíbrio entre os litigantes, fornecedor e consumidor, pois a inversão do ônus da prova zela pelo princípio da igualdade e garante a efetividade dos direitos individuas e coletivos.

Sendo assim, o presente artigo tem por objetivo verificar o benefício da inversão do ônus da prova na relação entre consumidor e fornecedor. O tema proposto se justifica pela fundamental importância de se buscar o equilíbrio processual entre as partes - consumidor e fornecedor - tendo em vista que aquele, na maioria das vezes, é a parte mais vulnerável na relação processual.

\section{METODOLOGIA}

Utilizou-se como metodologia a pesquisa eminentemente bibliográfica e exploratória, possibilitando a compreensão dos benefícios da inversão do ônus da prova na relação consumerista, facilitando a defesa da parte mais fraca, ou seja, do consumidor, trazendo soluções práticas e equilíbrio processual a todos os envolvidos.

\section{DISCUSSÃO}

A palavra prova tem sua origem do latim probatio, derivado do verbo probare, que significar provar, verificar (NOGUEIRA, 2000). Para Marinoni (2009, p. 57) a prova, em direito processual civil, "é todo meio retórico, regulado pela lei, e dirigido, dentro dos parâmetros fixados pelo direito e de critérios racionais, a convencer o Estado-juiz da validade das preposições, objeto de impugnação, feitas no processo".

Assim, a prova se mostra como "verdadeiro instrumento que possibilita ao juiz e às partes reconstruir acontecimentos pretéritos, permitindo ao primeiro usar desta reconstrução histórica para pôr fim ao conflito social que lhe foi trazido a exame" (BELLINI JÚNIOR, 2006, p. 15-16). A finalidade da prova é de "formar a convicção do juiz, permitindo-lhe, por meio do convencimento, compor a lide" (SANTOS, 2002, p. 62), ou seja, de mostrar a veracidade dos fatos em que o juiz irá se pautar para decidir.

A palavra ônus vem do "latim ônus, que é sinônimo de carga, fardo, peso" (NOGUEIRA, 2000, p. 72). Ônus é o "encargo cuja inobservância pode colocar o sujeito numa situação de desvantagem" (DIDIER JÚNIOR, 2013, p. 81). Ônus da prova "é senão o encargo de provar, no sentido de interesse, ou necessidade de a parte trazer provas de sua alegação para a formação da conviç̧ão do juiz" (MERGULHÃO, 2010, p. 61).

Convém mencionar que ônus e obrigação têm conceitos distintos, conforme explica Pacífico (2000, p. 36-37):

\footnotetext{
${ }^{1}$ Art. 6o São direitos básicos do consumidor:

$[\ldots]$

VIII - a facilitação da defesa de seus direitos, inclusive com a inversão do ônus da prova, a seu favor, no processo civil, quando, a critério do juiz, for verossímil a alegação ou quando for ele hipossuficiente, segundo as regras ordinárias de experiências.
} 
Em resumo, pode se concluir que os conceitos de ônus e de obrigação são heterogêneos, sendo inaceitáveis as teorias que os aproximam. No ônus, o sujeito é livre para adotar a conduta prescrita pela norma, não estando juridicamente vinculado ao seu cumprimento em favor de outro, como ocorre na obrigação. O não exercício de um ônus não configura ato ilícito e não é sancionado, enquanto a violação de uma obrigação é ilícita e sancionada. A norma estatuidora de um ônus tutela interesse do próprio onerado, ao passo que a norma portadora de uma obrigação tutela interesse do titular do direito subjetivo correspondente, que pode exigir seu cumprimento.

Acrescenta Bellini Junior (2006, p. 37, grifo do autor) que "nosso código processual prestigia a regra latina actori onus probandi incumbit, ou seja, que cabe ao autor o ônus da prova dos fatos em que se fundamenta seu direito". Assim, se não provado pelo autor o fato constitutivo, o réu será absolvido.

Por outro lado, caberá o ônus de provar ao réu quando alegar prova contrária aos fatos constitutivos do direito do autor, ou seja, incumbe ao réu demonstrar os fatos impeditivos, extintivos ou modificativos do direito do autor. Assim, ao réu cabe provar os fatos que, de modo direito ou indireto, atestam a inexistência dos fatos constitutivos deduzidos pelo autor.

\section{A INVERSÃO DO ÔNUS DA PROVA NO CÓDIGO DE DEFESA DO CONSUMIDOR}

O Código de Defesa do Consumidor dispõe no artigo $6^{\circ}$; $\mathrm{VIII}^{2}$, um dos direitos básicos do consumidor, qual seja, a facilitação da defesa de seus direitos, inclusive com a inversão do ônus da prova, a seu favor, no processo civil, quando, a critério do juiz, for verossímil a alegação ou quando for ele hipossuficiente, segundo as regras ordinárias de experiências.

Assim, a "inversão deriva do latim inversio, é a ação de inverter ou de mudar uma coisa em outra" (BELLINI JÚNIOR, 2006, p. 69). Demonstrando o consumidor sua hipossuficiência ou indicando a semelhança com a verdade de sua alegação, o juiz deverá inverter o ônus da prova. Nesse sentido, afirma Nogueira (2000, p. 24) que a "inversão ou não do ônus não fica a critério do juiz, pois estando indicadas nos autos qualquer das duas hipóteses, ele terá o dever de assim proceder".

Antes de analisar os requisitos para a inversão do ônus da prova, importante verificar, porém, os conceitos de consumidor e fornecedor, como também os objetos da relação de consumo, produtos e serviços.

Na definição do artigo $2^{\circ}$ do Código de Defesa do Consumidor, verifica-se que 'consumidor é toda pessoa física ou jurídica que adquire ou utiliza produto ou serviço como destinatário final'. Para Cintra (2011, p. 1) o conceito de consumidor tem "caráter fático econômico, visto que ocupa o último lugar na cadeia de consumo, já que o produto ou serviço é adquirido não para revenda e nem para emprego em processo de produção".

Ressalta-se que tanto a pessoa física como também a jurídica podem ocupar a posição de consumidor de consumo. A pessoa jurídica será consumidora quando os bens adquiridos sejam de consumo e não de capital e, no caso de serviços, quando contrata para a satisfação de uma necessidade que lhe é própria ou lhe é imposta por lei ou é da natureza de seu negócio, sem qualquer ligação com os insumos da produção (FILOMENO, 2011).

Já o artigo 3ㅇ do mesmo diploma legal conceitua fornecedor como 'toda pessoa física ou jurídica, pública ou privada, nacional ou estrangeira, bem como os entes despersonalizados, que desenvolvem atividade de produção, montagem, criação, construção, transformação, importação, exportação, distribuição ou comercialização de produtos ou prestação de serviços'. Nesse sentido, afirma Cintra (2011, p. 6, grifo do autor) que:

\footnotetext{
${ }^{2}$ Art. 60 São direitos básicos do consumidor:

$[\ldots]$

VIII - a facilitação da defesa de seus direitos, inclusive com a inversão do ônus da prova, a seu favor, no processo civil, quando, a critério do juiz, for verossímil a alegação ou quando for ele hipossuficiente, segundo as regras ordinárias de experiências.
} 
Tanto pessoa física como jurídica podem ser também fornecedores. Agora, o legislador ainda ressalva que tanto pessoa pública como privada podem ser fornecedores, desde que desempenhem atividade de transformação (lato sensu), importação ou comercialização (esses três núcleos abrangem todos os demais) de produto. A palavra chave é HABITUALIDADE. [...] De maneira geral, o código conceitua como fornecedor todos aqueles responsáveis pela colocação do produto no mercado brasileiro.

O Código de Defesa do Consumidor também define, em seu §1어 do artigo 3으, produto como sendo 'qualquer bem, móvel ou imóvel, material ou imaterial'. Prevalece o entendimento na doutrina de que o legislador deveria ter se utilizado do vocábulo bens ao invés do vocábulo produto, "o primeiro termo retrorreferido é muito mais abrangente e, aliás, mais técnico tanto do ponto de vista jurídico, como do ponto de vista da econômica política" (FILOMENO, 2015, p. 48).

Por fim, o §2으 do artigo 3ำ, do Código de Defesa do Consumidor define serviço como sendo 'qualquer atividade fornecida no mercado de consumo, mediante remuneração, inclusive as de natureza bancária, financeira, de crédito e securitária, salvo as decorrentes das relações de caráter trabalhista'. Assim, para Filomeno (2015, p. 49), o código consumerista "abrange todo e qualquer tipo de serviço, entendido como uma utilidade usufruída pelo consumidor, e prestada por um fornecedor determinado, num facere (fazer)".

Sendo assim, toda relação jurídica de consumo pressupõe dois polos de interesses - o consumidor e o fornecedor - e a coisa, que é objeto desses mesmos interesses, sendo no caso um produto ou um serviço. Portanto, quando se fala em relação de consumo, o Código de Defesa do Consumidor é o ponto de partida, aplicando-se de forma subsidiária, as regras do Código de Processo Civil, de maneira que não se oponha as disposições protecionistas do consumidor.

\section{DOS REQUISITOS LEGAIS: HIPOSSUFICIÊNCIA E VEROSSIMILHANÇA}

Importante destacar que a possibilidade da inversão do ônus da prova prevista na lei consumerista, não teve o propósito de liberar o consumidor do encargo probatório previsto na lei processual civil, mas tão somente o de superar as dificuldades técnicas na produção das provas necessárias à defesa de seus direitos em juízo. Vale ressaltar que direito do consumidor funda-se na vulnerabilidade do consumidor.

Assim, o elemento informador das normas de proteção ao consumidor se dá pelo princípio da vulnerabilidade, ou seja, a partir da ideia básica de proteção de um determinado sujeito: o consumidor, por ser ele vulnerável. Ensina Cavalieri Filho (2014, p. 49) que "vulnerabilidade é um estado da pessoa, uma situação permanente ou provisória que fragiliza o consumidor. Há uma presunção absoluta de vulnerabilidade, iuris et iure em favor de todos os consumidores".

Logo, o princípio da vulnerabilidade, expresso no artigo $4 \stackrel{0}{ } \mathrm{I}^{3}$, do Código de Defesa do Consumidor, possui presunção absoluta, pois decorre da lei, do Direito Material para todos os consumidores. Sendo assim, segundo o direito material, todo consumidor é vulnerável quando possui uma relação de consumo com o fornecedor. Nesse sentido, verifica-se que o princípio da vulnerabilidade decorre diretamente do princípio da igualdade, posto que "reconhecendo-se a desigualdade existente, busca-se estabelecer uma igualdade real entre as partes nas relações de consumo" (CAVALIERI FILHO, 2014, p. 48).

Nas ações em que se discute relação de consumo existe regra especial que autoriza em certos casos, a inversão do ônus da prova, transferindo-o do autor (consumidor) para o réu (fornecedor). Dessa forma, para que haja a inversão do ônus da prova devem-se verificar os requisitos indicados no texto legal: a) hipossuficiência do consumidor; e b) verossimilhança de suas alegações.

\footnotetext{
${ }^{3}$ Art. 40 A Política Nacional das Relações de Consumo tem por objetivo o atendimento das necessidades dos consumidores, o respeito à sua dignidade, saúde e segurança, a proteção de seus interesses econômicos, a melhoria da sua qualidade de vida, bem como a transparência e harmonia das relações de consumo, atendidos os seguintes princípios:

I - reconhecimento da vulnerabilidade do consumidor no mercado de consumo.
} 
Vale destacar a controvérsia existente na doutrina em relação à cumulatividade ou alternatividade dos requisitos legais para a inversão do ônus da prova. A corrente minoritária defende que é necessário à presença dos dois requisitos para que o juiz possa deferir a inversão do ônus da prova, ou seja, é necessário que a alegação do consumidor seja verossímil e também deve ser ele hipossuficiente. Portanto, trata-se de requisitos cumulativos.

Por sua vez, a corrente majoritária entende que realizando uma análise do texto legal (art. 60, inciso VIII), "mostra-se exata a utilização da conjunção alternativa ou, uma vez que trata-se de exigências não cumulativas, bastando, portanto, para a inversão, a ocorrência de apenas uma das hipóteses aventadas" (ARAÚJO FILHO, 2009, p. 7, grifo do autor). Portanto, constata-se que a inversão se dará a critério do juiz quando a alegação for verossímil ou quando o consumidor for hipossuficiente.

\section{a) hipossuficiência do consumidor}

A hipossuficiência do consumidor é um dos requisitos para que o juiz possa inverter o ônus probatório. Vale ressaltar que há um conceito errôneo difundido de que as normas consumeristas veio para proteger o consumidor que é parte economicamente mais fraca frente ao fornecedor. Dessa forma, o conceito de hipossuficiência acaba sendo associado à ideia de desproporção financeira.

Para Cavalieri Filho (2014, p. 49, grifo do autor) hipossuficiência é um "agravamento da situação de vulnerabilidade, um plus, uma vulnerabilidade qualificada. Além de vulnerável, o consumidor vê-se agravado nessa situação por sua condição individual de carência cultural, material ou ambos". Segundo Araújo Filho (2009, p. 13, grifo do autor):

A hipossuficiência do consumidor deve ser interpretada em sintonia com a sua vulnerabilidade no mercado de consumo, devendo ser reconhecido todas as vezes que, por sua situação de inferioridade em relação ao fornecedor, seja do ponto de visto econômico ou cultural, seja sob o aspecto do acesso a informação, do pleno conhecimento sobre os elementos técnicos do produto ou do serviço, ou da carência de estrutura organizacional, a produção da prova se mostre mais fácil ao fornecedor, ou deva simplesmente ser a ele imposta, como natural assunção dos riscos da atividade empresarial.

Sendo assim, o significado de hipossuficiência no texto normativo consumerista é técnico e não econômico. Dessa forma, vulnerabilidade e hipossuficiência não se confundem, eis que todo consumidor é vulnerável, mas nem todos são hipossuficientes no sentido processual, ou seja, "nem sempre estará desprovido de meios técnico-processuais para promover a prova do fato constitutivo do seu direito" (THEODORO JÚNIOR, 2013, p. 466).

Verifica-se, portanto, que o Código de Defesa do Consumidor utilizou-se da expressão hipossuficiência para as hipóteses de inversão do ônus da prova, a ser determinada pelo juiz em face do caso concreto. Nesse sentido, se, no caso concreto, o juiz verificar que não se deu a referida dificuldade técnica, não poderá inverter o ônus da prova, apenas diante da vulnerabilidade genericamente reconhecida pela lei consumerista.

b) verossimilhança de suas alegações

O outro requisito para que o juiz conceda a inversão do ônus da prova decorre de que as alegações do consumidor sejam verossímeis, ou seja, que as alegações sejam semelhantes com a verdade. O vocábulo verossímil "significa semelhante à verdade ou que tem aparência de ser verdadeiro" (SANTOS, 2002, p. 72). Desse modo, a verossimilhança não exige a certeza da verdade. Para Araújo Filho (2009, p. 8, grifo do autor):

Cumpre sustentar que a exigência de ser verossímil a alegação deve ser interpretada amplamente, no sentido de parecer verdadeiro, de não repugnar à verdade, segundo as regas ordinárias de experiência, o fato alegado, se ser plausível o caso narrado pelo 
consumidor, sem todavia ser necessário que o fato descrito se mostre provável, que tenha efetiva probabilidade de ser verdadeiro.

Assim, deve existir uma aparente verdade apresentada nas alegações do autor se comparadas às regras de experiência, devendo o juiz diante do caso concreto determinar a inversão. Nesse sentido, parecendo ser verossímil o fato alegado pelo consumidor, mesmo não havendo provas, ou sendo precárias as provas produzidas, deve o juiz inverter o ônus da prova.

\section{CONCLUSÃO}

O Código de Defesa do Consumidor entrou em vigor para dar uma maior proteção ao consumidor, trazendo, entre vários direitos, a inversão do ônus da prova a seu favor, como um direito básico. A inversão do ônus da prova na relação processual consumerista tem como objetivo auxiliar o consumidor que por motivo de desprovimento técnico ou econômico possa ser prejudicado.

Dessa forma, como todo consumidor é considerado vulnerável pelo direito material consumerista, o juiz poderá determinar a inversão do ônus da prova, a seu critério, desde que fique constatado a verossimilhança das alegações do consumidor ou a sua hipossuficiência, trazendo como benefício o equilíbrio processual, onde o consumidor e fornecedor passem a ter o mesma igualdade, com as mesmas chances de mostrar suas motivações em juízo.

Portanto, é possível concluir que o sistema legal consumerista veio proteger o consumidor por ser a parte vulnerável nas relações de consumo. Além disso, em um caso concreto, estando presente a verossimilhança das alegações do consumidor ou sua hipossuficiência em relação ao fornecedor, a inversão do ônus da prova vem justamente em benefício daquele, não para prejudicar este, mas para equilibrar a relação consumerista, salvaguardando, dessa forma, a facilitação da defesa do consumidor em juízo.

\section{REFERÊNCIAS BIBLIOGRÁFICAS}

ARAÚJO FILHO, Luiz Paulo da Silva. Comentários ao código de defesa do consumidor: direito processual: arts. 6ำ, VIII, 38 e 81 a 119. 2. ed., rev. e atual. São Paulo: Saraiva, 2009.

BELLINI JÚNIOR, Antonio Carlos. A inversão do ônus da prova. Campinas: Servanda, 2006.

CAVALIERI FILHO, Sergio. Programa de direito do consumidor. 4. ed. São Paulo: atlas, 2014.

CINTRA, Antonio Carlos Fontes. Direito do consumidor. Niterói, RJ: Impetus, 2011.

DIDIER JÚNIOR, Fredie. Curso de direito processual civil: volume 2: teoria da prova, direito probatório, ações probatórias, decisão, precedente, coisa julgada e antecipação dos efeitos da tutela. 8. ed., rev., ampl. e atual. Salvador: JusPODIVM, 2013.

FILOMENO, José Geraldo Brito. Dos direitos do consumidor. In: GRINOVER, Ada Pellegrini et al. Código brasileiro de defesa do consumidor: comentado pelos autores do anteprojeto. 10. ed., rev., atual. e ampl. Rio de Janeiro: Forense Universitária, 2011, v. I, p. 9-177.

. Manual de direitos do consumidor. 13. ed. São Paulo: Atlas, 2015.

MARINONI, Luiz Guilherme. Prova. São Paulo: Revista dos Tribunais, 2009.

MERGULHÃO, Rossana Teresa Curioni. A produção da prova no direito processual: o alcance e os limites do direito processual. Belo Horizonte: Del Rey, 2010. 
NOGUEIRA, Tania Lis Tizzoni. A prova no direito do consumidor: o ônus da prova no direito das relações de consumo. 1. ed. Curitiba:Juruá, 2000.

PACÍFICO, Luiz Eduardo Boaventura. O ônus da prova no direito processual civil. São Paulo: Revista dos Tribunais, 2000.

SANTOS, Sandra Aparecida Sá dos. A inversão do ônus da prova: como garantia constitucional do devido processo legal. São Paulo: Revista dos Tribunais, 2002.

THEODORO JÚNIOR, Humberto. Curso de direito processual civil: teoria geral do direito processual civil e processo de conhecimento. 54. ed. Rio de Janeiro: Forense, 2013, v. 1. 